\title{
Khat in the Horn of Africa: Historical perspectives and current trends
}

\author{
Ezekiel Gebissa* \\ Kettering University, Liberal Studies, 1700 University Ave, Flint, MI 48504, United States
}

\section{A R T I C L E I N F O}

\section{Article history:}

Received 30 October 2009

Received in revised form

31 December 2009

Accepted 19 January 2010

Available online 19 March 2010

\section{Keywords:}

Khat

Cathinone

Commercialization

Traditional-use

Illicit drug

International control

\begin{abstract}
A B S T R A C T
Aim of the study: This article looks at the history of the expansion of khat consumption from the traditional chew regions to Western countries and assesses the implication of possible international control for its use and trade in the Horn of Africa.

Materials and methods: Ten months of initial field work in Ethiopia, three follow up field work, archival work in Ethiopia and Europe, as well as study of available relevant literature.

Results: The debut of khat in the West in the 1980s was initially greeted with disdain and indifference. Authorities dismissed it on grounds that the mode of consumption, chewing the leaves for an extended period of time to extract a miniscule amount of the active ingredient, would not be appealing to Western users. Following the Mogadishu debacle of 1993, as depicted in the movie Black Hawk Down, authorities in the West began to express concern that khat was a new drug of abuse. Its trade was increasingly linked with terrorism because of its association with immigrants from the traditional khat use countries in the Horn of Africa and the Arabian Peninsula. Amid hysteria and moral panic, many Western countries classified khat as a highly potent controlled substance, rendering its possession, cultivation, and trade illegal.

Conclusion: This article argues that more and more Western governments, out of panic rather than definitive evidence of harm, will be instituting national laws banning the leaves, but khat will not be placed under international control because the scientific evidence of harm is unlikely to rise to a critical mass that would justify its illegalization. States in the source countries would continue to tolerate khat because banning it would be disastrous from an economic and social welfare standpoint. Because of its ambiguous legal position and the unstable nature of its active ingredient, cathinone, khat would not be successfully commoditized as a global commodity or transformed into a highly concentrated illicit drug. In this situation, khat would continue to be chewed in the traditional-use areas of the Red Sea littoral marketed by local syndicates who work with a large network of petty commodity traders.
\end{abstract}

(C) 2010 Elsevier Ireland Ltd. All rights reserved.

\section{Introduction}

The use of psychoactive substances in religious and healing rituals, in semi-ritual practices which reinforce social and political bonds, and simply as recreational activity is a universal cultural practice (Steinberg, 2004, pp. 3-4). In indigenous societies the practice is often governed by an evolved tradition and etiquette that place strictures on misuse (Gebissa, 2004). Outside the traditional environment, the substances enter a complex arena where the use of psychoactive plant substances or their derivatives leaves a trail of destruction in its wake, provoking collective responses, both official and private. Many drugs of abuse in the West today, such as heroin and cocaine, were once plant products used for religious, medicinal and ritualistic purposes, but became

\footnotetext{
* Tel.: +1 8107627891 .

E-mail address: egebissa@kettering.edu.
}

objects of abuse in the hands of persons and groups not subject to cultural proscriptions. As the harmful aspects of the nontraditional uses multiplied, authorities targeted for destruction not just the abusers but also the indigenous producers and the traditional practices in the traditional-use areas (Smith et al., 1992, pp. xi-xiv).

In the last two decades, khat, a psychoactive shrub chewed for its stimulating effects, has followed immigrants from the traditionaluse regions of the Horn of Africa and the Middle East to Western counties. Many in the West have responded to its debut with the same kind of reaction they had shown to other psychotropic plants in past centuries. Khat can now be regarded as a psychoactive plant taken out of its cultural environment, used in new settings, perceived as an object of abuse and targeted for elimination (Carrier, 2007, pp. 195-201; Grayson, 2008, pp.95-97, 116-124). While khat has yet to cross the line of becoming a new drug of abuse, it has come to a crossroads of either following the course of the mild stimulants such as coffee, tea, and sugar that have now been successfully com- 
mercialized and globalized or of the highly refined products such as cocaine or heroin that are universally considered harmful and are under international control. ${ }^{1}$

The fact of khat's appearance in the West has nevertheless created moral and political panic in some circles (Carrier, 2007, pp. 195-203) and growing anxiety in the source countries because of the fear that the countries that have hitherto kept khat legal might yield to pressure to outlaw its use and trade, culminating in placing khat under international control. There is concern that once this occurs, local prohibitionist movements, with anticipated moral and possibly material support from the most powerful states in the world, would bring pressure on the source countries to suppress the cultivation of the plant. In the countries where khat use is associated with a lifestyle, and its cultivation a strategy of national development, a ban would have powerful political and economic implications.

In both cases, the fear may be unjustified. Despite some hysteria in some Western countries, khat use has not spread beyond immigrant communities that hail from the Horn of Africa. I argue that despite the spread of the chew culture to the West, unless khat is successfully commercialized as a legal commodity or as a highly potent illicit derivative, it will remain a regional commodity whose production is controlled by smallholder producers and its trade by local syndicates that work with a large network of private operators (Gebissa, 2004; Anderson et al., 2007). This is not so much because of the oft-cited complacent attitude regarding the growing of khat on the part of Horn of Africa governments who rely on revenues from khat transactions, but rather due to khat's distinctive features, such as the necessity to chew green khat leaves when they are fresh and moist, that militate against its successful commercialization, legal classification, and production of a more definitive knowledge about its effects on the user's health. Here a brief historical context of khat consumption and the controversy surrounding its use is in order. While khat use has been known in East Africa and the Middle East for a long time, this article focuses largely on the Horn of Africa.

\section{Historical perspectives}

With regard to consumption, it is important to note that khat chewing has a long history in the Horn of Africa. Reports of khat use in the hinterlands of the Horn of Africa go back at least eight centuries. The leaves were chewed by the people in the medieval Islamic sultanates of the southern region of today's Ethiopia as early as the fourteenth century. From there, the chew culture spread to the Horn region along the historic long-distance trading routes that connected Muslim trading states with each other and with the Indian Ocean world. By the mid-nineteenth century, the plant was used for a variety of purposes in the region that is now Ethiopia. In the Kingdom of Shawa (central Ethiopia) and in Kaffa (southwestern Ethiopia) the plant was extensively cultivated and used (Beke, 1843 , p. 263; Harris, 1844 , pp. 334-335). In the Tigray region in the north, khat was used for enhancing the flavor of a local drink made of honey (Férret and Galinier, c. 1848, p. 109). In eastern Ethiopia, specifically in the Harer highlands, khat consumption had assumed the chew features that are quite familiar today (Moktar, 1876, pp. 369-372; Burton, 1966, p. 31). Beginning in the early twentieth century, its consumption was transformed from a luxury enjoyed

\footnotetext{
1 That khat is at the present at this crossroads is evident in the various reactions of governments in the West, which range from outlawing to tolerating consumption of the leaves, and in newspaper headlines such as, "Khat: Harmless stimulant or dangerous drug? (Nasrulla, 2000); Khat: Harmless habit or dangerous drug? (Summers, 2006); "Flower of Paradise" or Dangerous Stimulant?; "Khat: Is it more Coffee or Cocaine? (Dizikes, 2009).
}

by the urban elite to a cultural practice performed by a significant portion of the population in the region and, after the 1930s, to a commonplace pastime activity of nearly all social classes, cultural categories and religious affiliations. Today, regional and countrywide surveys reveal that an average of 30 percent of Ethiopians are regular khat chewers (Belew et al., 2000, p. 32; Arrafaine, 2004).

In northwestern Somalia (the Republic of Somaliland), the practice of chewing goes back several centuries. Al-Maqrizi (1364-1442), the fifteenth-century Egyptian historian and geographer, states that the people of Zeyla chewed "the leaves of a plant which enhances intelligent performances, produces appreciable sense of hilarity while depressing appetites for food and sex and repelling sleep" (cited in El-Mahi, 1972). By the late nineteenth century, khat chewing must have been so widespread in Zeyla that Sayid Mahamed Abdille Hasan, the Somali nationalist leader and poet, condemned the members of the Sufi Order in the town for promoting the leaves as a plant that Allah revealed to the faithful to help them stay awake for prayer during the month of Ramadan (Hassan, 2001, p. 193). The level of consumption must have reached a critical point obliging British authorities of the Somaliland Protectorate to pass a law in 1921 forbidding the cultivation, import, and sale of khat (Elmi, 1984, p. 274). In 1936, official reports show the Somaliland Protectorate imported 4000 bundles (approximately $4000 \mathrm{~kg}$ ) of khat, in addition to the amount smuggled across the border to evade the restriction imposed by the British ban (Geshekter, 1985, p. 32). During the Second World War, khat consumption not only increased in the border towns but also extended deep into the protectorate owing to the connection by modern transportation of the Protectorate with the khat producing areas of the Harerge highlands and the migration of a considerable number of Somali pastoralists to urban centers. By 1945, according to the estimate of the British consul in Harer, about $3000 \mathrm{~kg}$ of khat were smuggled daily into the Protectorate (Gebissa, 2004, p. 81).

In southern Somalia, the existing literature suggests that khat consumption was virtually unknown prior to the Second World War. It is said that local customs prohibited khat use and Italian authorities strictly enforced a law they had promulgated, often by burning khat they found in the territory. The fact that the Italians had to resort to scorching tactics indicates the use of khat here had a more longstanding history than previously acknowledged. When the British took control of all of Somali territories in 1941 , the process of integration of the two territories was initiated, thereby making business and cultural exchange possible. In the 1950s, khat chewing spread to southern Somalia as more and more Somalis took up the habit as an act of defiance against colonial authority (Geshekter, 1985, p. 32). In the 1960s, independence and integration of the former Italian and Ethiopian colonial territories allowed for the khat chewing habit to flow southward unencumbered. Within two decades, khat reportedly became the dominant feature in all walks of life. By the early 1980s, khat chewing had become a significant part of the social fabric of Somali society and a catalyst for communication, conviviality, and commerce (Hassan, 2001, pp. 192-193). The importance of khat is reflected in the fact that in 1983 Somalia spent \$57 million, an amount equivalent to 5.7 percent of the GDP, on importing khat (Elmi, 1984, p. 280).

In Djibouti khat has been consumed since the creation of the port in 1869. At the time, the chewers were mostly Yemeni Arabs who, from the founding of the port, constituted a substantial element of the city's population. For Yemeni Arabs, khat chewing had been a long-standing and widespread practice over many centuries. When they immigrated to other regions, Yemenis took the custom to their destinations, including to Israel (Derfner, 1996). In the context of Djibouti's hot climate and Islamic prohibition of alcohol, khat was the only luxury on which most well-off Yemeni Arabs were willing to spend a considerable amount of money. Over time, Djibouti's 
indigenous residents embraced khat chewing as a practice of their Islamic faith and a culture of the people who spoke the language of the Prophet (Thompson and Adloff, 1968, pp. 31-33). Supplied by dhow from Yemen and after 1902 by train from the Harerge highlands, by the 1940s, chewing had become a widespread ritual practiced by a significant portion of the city's residents. Today, khat chewing in Djibouti is a ubiquitous practice involving the majority of the country's citizens. Every member of society, from the pauper on the streets to the president in the palace, chews khat, regardless of economic and social background. Some chew to escape the miseries of a poverty-stricken life, others to keep them away from the searing sun, and still others simply to indulge in a luxury (Fedarko, 2006).

This has prompted observers, such as Kevin Fedarko of Esquire magazine to describe Djibouti society as a narco-society, not because khat is a narcotic substance, but to denote the level of pervasiveness of its use. In this country, up to 56 percent of households have at least one user while as much as 80 percent of the adult population is said to chew the leaves regularly (Brown, 2009, p. 1; Borelli, 2009, pp. 564). In a country where unemployment reaches up to 60 percent (Kimball, 2007), chewers are willing to spend as much as a third and, in some cases, half of their household income on the leaves. And a casual interview on the streets of Djibouti as to why they spend money they do not have on khat elicits responses such as these: "Everything we do depends on our majesty, khat" and "khat is my brother. It takes care of everything." Some chewers, echoing Karl Marx's "opiate of the masses" dictum, invoke a more incidious conspiracy that, "if there was no khat, we'd have to think about more serious things, like crticizing the government" (Bengall, 2006). Either way, khat chewing has become a national institution in Djibouti.

That khat has been used in the Horn of Africa for centuries does not mean that the practice of chewing the leaves enjoyed widesperead acceptance. From time to time, controversy over khat had erupted in several countries. In the nineteenth century, the founders of the Sufi Qadria Order in Somalia debated whether khat was "food of the saints" or a "satanic act." Sayid Mahamed Abdille Hasan reportedly stated that khat chewing had the blessing of the revered founders of the Qadriya Order, such as Ismail Mogadishu, but also attacked and banned the chewing of khat in Berbera because the practice was not compatible with an Islamic code of behavior (Hassan, 2001, pp. 192-193). It is a debate that has continued in Somali society to this day.

In Ethiopia, khat has been an issue of controversy since the early part of the twentieth century. As in Somalia and Yemen, the ulama in Harer were divided on the issue, some condemning it as a substance prohibited by the Prophet and others arguing that it was the only plant Allah revealed to the pious as a sleep repellent that aids prayer (Brooke, 1960, p. 53). In the Harerge province, the controversy was between the Christian rulers from central and northern Ethiopia who considered khat chewing a mark of apostasy and the local Muslim Oromo, Somali, and Hareri peoples. In fact, khat chewing was viewed as un-Christian in that it was cited as one of the reasons for deposing the Christian emperor Lij Iyasu in 1916 (Ali, 1985, p. 12).

Beyond national debates, khat has been a thorny issue in interstate relations in the Horn. While khat's alleged adverse health effects have always been cited, the contentious issue among the countries has been the negative impact of the trade on the consumer nations' balance of payments (Distefano, 1984, pp. 264-265). In the early 1940s, concern about khat in draining away wealth to Ethiopia was an issue cited by authorities in the Somaliland Protectorate when they banned surface conveyance to fight smuggling. After independence, the drive to stop khat gathered momentum, particularly when Somalia sent its forces into Ethiopia in 1963. A year later, Somalia banned Ethiopia's khat (Brooke, 1960, p. 57;
Gebissa, 2004). The effect was an increased level of smuggling along the more than $1000 \mathrm{~km}$ border between the two countries.

Even though Ethiopia has been the primary beneficiary of khat exports, the government has occasionally shown a propensity to use khat for political reasons. During the 1964 Ethio-Somali War, for instance, Ethiopian authorities withheld khat from Somalia, in the hope that the lack of the leaves might incite the Somalis against their government. Following the war, the ban was lifted after the commanding military general in the region argued in favor of an unrestricted flow of khat into Somalia. His rationale was that increased khat would turn Somalia into a country of physically unfit and psychologically incompetent addicts who would not be able to field an effective fighting force and devastate their country's economy by draining money into Ethiopia (Gebissa, 2004, pp. 104-105).

Khat has been an indissoluble link between Ethiopia and Djibouti in which the latter has little power to implement a national policy. In 1952, the French colonial administration imposed taxes on khat transactions for the first time to reduce its importation. Official imports nevertheless held steady and consumption tripled in three years, thereafter showing growth with increases in the minimum wage. Successive colonial governors inveighed against the alleged evils of khat and took measures to limit importation or consumption, only to see increased smuggling, the loss of government revenue, and widespread rioting (Thompson and Adloff, 1968, p. 164). In view of its dependence on Ethiopia, no government in Djibouti has ever attempted to antagonize the big neighbor to the West by banning khat. Djibouti is a case where, in spite of the local resistance to banning khat, Ethiopia could forcibly export khat.

\section{Current state}

The longstanding controversy largely confined to the Horn of Africa has now escalated into a matter of international concern following the emergence in the early 1990s of khat use in the West. The moral and political panic that ensued evokes the same kind of moral outrage that other psychotropic substances, such as coffee and tea, had touched off in Europe in the seventeenth century (Pendergrast, 2000). Does the beginning of khat exports from the Horn countries to Europe, North America, and Australia represent the early stages of the establishment of khat as a global commodity?

In my view, the spread of the chew culture to the West is a function of the emigration of people from the Horn of Africa. However, the fact that khat is now chewed in some Western cities is not a sign of the leaf's emergence as a global commodity or an illicit drug of abuse. There is little chance, at least in the foreseeable future, that khat will be successfully commercialized as either a legal commodity or as an illicit drug. Khat will instead continue to play the role it has played for centuries in the Horn of Africa, and the primary market will remain confined to the communities in the region, perhaps slowly expanding its frontier into the Great Lakes region and southern Africa. There are four reasons why I maintain this perspective.

\subsection{Unstable cathinone}

First, khat cannot obtain a foothold in the West as a commodity because the highly unstable nature of cathinone militates strongly against its commercialization on a global scale. There is a long trail of failures that substantiate this point. As early as the late nineteenth century, some Europeans attempted to prepare some kind of khat-based beverage; others proposed to develop a pharmaceutical preparation to treat medical disorders. In 1910, some pharmacists in Lyon, France, marketed a pill called Neo-tonique Abyssine for treatment of nervous disorders. In 1913, a London 
chemist named W. Martindale sold preparations and pills based on khat extracts. Similar attempts at commercialization of khat were made in Switzerland. Like many of the plant drugs, such as tea or coffee, khat made its debut in Europe as an exotic medicine. But it failed to make the transition into a global commodity either as an object of popular pleasure or as a means to escape into the underground realm of a synthetic drug. It failed because of the difficulty involved in obtaining the leaves during the First World War. Given that the more important alkaloid in khat could not have survived the long journey, the logistical difficulties of speedy delivery militated against its potential success as a commodity.

Because of cathinone's volatility, khat may have missed the rare chance of getting on the bandwagon of major societal transformation that favored the successful commercialization of other commodities. For instance, it took sugar nearly five centuries to become a widely used commodity in Europe. As Sidney Mintz explains, the fact that sugar sweetened and made palatable bitter stimulants that arrived in England in the seventeenth century is only part of the reason why sugar became an established commodity. Indeed sugar's success was the direct consequence of the Industrial Revolution in England, which transformed sugar from an upper-class luxury into a working class necessity (Mintz, 1986, p. xxv). Coffee was also connected with the commercial revolution of the seventeenth century, which facilitated its expansion into Europe, the industrial revolution of the eighteenth century made it part of the diet of working people in Britian, and the American Revolution created a whole country of coffee drinkers (Pendergrast, 2000, pp. 3-20).

These two cases demonstrate that, as David Courtwright (2001, p. 69) has argued, "only drugs that were used widely in western societies became global commodities." To become a global commodity, khat needs to have a sustained demand in the West, which, in turn, requires mass consumption to generate sufficient revenue for Western governments to turn a blind eye towards khat. In short, the long and complex processes that made sugar and coffee global commodities and attracted large corporations to take up the trade mass consumption and large profit margins - do not exist today and may not exist as long as a mechanism to stabilize natural cathinone is not forthcoming.

Psychotropic substances, Courtwright (2001, p. 55) writes, can "become global commodities despite the efforts of police and customs, but they generally do so in such concentrated forms as heroin, cocaine, or hashish. Qat, by contrast, is bulky and difficult to conceal." In other words, khat needs some ingenious entrepreneur who would develop a highly sophisticated mechanism to extract cathinone and stabilize it in the region of its production. Illicit drug processing laboratories, of necessity, must be placed in remote locations to avoid detection and control. This is an unlikely scenario given the geography and topography of the Horn region. In any case, any such development would make khat an easy target for eradication in the same way coca leaves have been made so in Latin America. As it is, khat is a Schedule I or Class I drug in many countries in the West. The entrenched belief that khat might follow the trajectory of the more potent drugs now haunts authorities in many Western countries. Any evidence that khat is the raw material for a product that could potentially become a highly potent drug of abuse subject to control would not only force the international community to classify khat and adopt a law enforcement or "combat" approach against khat, it would also compel countries like Ethiopia to outlaw khat.

\subsection{Uncertain legality}

Another factor that forces khat into remaining confined to the Horn region and continuing as a regional commodity is its ambiguous position as a legal vegetable in some counties, a quasi-legal agricultural product in others, and an illegal substance in still others. As such, khat will have little appeal to multinational corporations that often tend to commercialize and globalize only commodities that are legal-intending to profit from mass marketing. It will not be attractive to criminal cartels either because they derive their enormous profit from the high risk associated with dealing in illegal commodities. ${ }^{2}$ What will determine khat's future is whether the plant will remain in this legal limbo that favors the status quo or whether it will be placed under international control, thus driving up price and increasing the likelihood of khat escaping into the underground realm operated by criminal networks.

Advocates of prohibition, at least those in Ethiopia and perhaps elsewhere in the Horn, insist that "the United Nations has established" that khat is a "narcotic" drug (Addis Reporter, 2004; Letters from anti-khat groups to me, 2004). This is stretching the facts. International organizations began to address the problems associated with khat as early as 1933, when the League of Nations Advisory Committee on the Traffic of Dangerous Drugs discussed two technical reports on the subject of khat. In 1957, the United Nations Commission on Narcotic Drugs was asked to take up the question and make recommendations on whether khat should be internationally classified as an illegal drug. The investigations in both cases failed to establish clear evidence of the harmful effects of khat consumption. A study commissioned by the UN produced a report in 1975 that determined cathinone to be the active ingredient that gives fresh khat its potency. Previously, cathine, which is basically ephedrine, was believed to be the main active ingredient. Cathinone is many times more powerful, similar to amphetamine in its makeup, but half as potent. In 1986 the United Nations finally added cathinone, but not the khat plant, to its list of substances that should be regulated. In fact, the United Nations Office on Drugs and Crime is quite explicit that the khat plant is a stimulant "not subject to international control" (UNODC, 1996). In 2006, the World Health Organization Expert Committee "concluded that the potential for abuse and dependence was low and that the level of abuse and threat to public health was not significant enough to warrant international control. Therefore, the Committee did not recommend the scheduling of khat" (WHO Expert Committee on Drug Dependence, 2006, pp. 11-12). Seventy years after the international community first took up the issue of khat, there still is not a clear-cut answer, but it is clear that khat is not under international control.

At other times, the prohibitionists point to such specific national policies as in the case of the United States to establish that khat is a controlled substance. Indeed some governments have made decisions ostensibly based on national laws. Wherever khat is banned, it is not science or careful implementation of applicable laws that led to policy decisions. In the often cited case of the United States, the Drug Enforcement Agency (DEA), which only a few years prior dismissed khat as a substance unappealing to Western users, classified khat as a Schedule I controlled substance in 1993, following the botched operation by US Special Forces in Mogadishu, Somalia (Anderson and Carrier, 2007, p. 150; Beckerleg, 2008). After 9/11, in their public pronouncements, DEA officials began to link khat chewing with terrorism. "It is not coffee. It is definitely not like coffee," said one DEA official in 2007, "It is the same drug used by young kids who go out and shoot people in Africa, Iraq and Afghanistan. It is something that gives you a heightened sense of invincibility, and when you look at those effects, you could take out the word 'khat' and put in 'heroin' or 'cocaine"' (Dizikes, 2009).

\footnotetext{
2 According to Davenport-Hines (2001), illicit drug traffickers have gross profit margins of up to $300 \%$. They could absorb a large loss, at least $75 \%$ of their shipments, before their profits could be hurt.
} 
Setting aside media reports, unofficial pronouncements, and government bulletins, the issue of khat's classification is not yet a settled matter even in the United States. Some US Circuit Courts have ruled that the khat plant, as opposed to the cathinone that may be found in it, "is not a controlled substance" because "neither the U.S. Code nor the Code of Federal Regulations" lists it as such. As a legal matter, therefore, "Khat itself is not illegal. Some of the chemicals that are sometimes found in it-but not always found in it-are illegal" (Armstrong, 2008, p. 637). The difference is, accoding to Sidney L. Moore, a defense attorney in New York specializing on khat, one needs "to chew about $650 \mathrm{lb}$ of khat to squeeze $1 \mathrm{gm}$ of cathinone out of it" (Gardiner, 2006). That is an impossible task even for the orally dexterous chewer. To illustrate, equating khat with cathinone is like equating coffee beans with caffeine, and coca leaves with cocaine.

Perhaps owing to their prior experience with khat control in the Somaliland Protectorate (1921-1957), the Aden Colony (1957-1958) and East Africa (1945-1956), the British adopted a process that contrasts with the United State's approach. When khat chewing showed up in the West, the British were one of the first to confront it. Instead of a moral panic that has characterized the reaction to khat elsewhere, the British took a more deliberative approach to formulate a policy response (Carrier, 2007, pp. 195-196). After commissioning private studies and parliamentary debate on khat, the Home Office asked the Advisory Council on the Misuse of Drugs (ACMD) to review the evidence on khat. In 2005, the Council determined that khat did not qualify as a controlled substance under existing UK laws and international conventions, but underscored the importance of education to discourage regular chewing (ACMD, 2005). In Britain, a decision was made that the harm khat might cause was not worth the social disruption and economic cost required to effect behavioral change.

Obviously, khat is not a controlled substance internationally and even national laws are a patchwork quilt of legal opinions. Its uncertain legal position, which I believe is going to be the situation for many years to come, makes it unattractive for multinational corporations to commercialize it for a global marketplace. The most important factor that induces corporations to get into the business of commercializing a product, as was mentioned earlier, is the potential for massive profit that is often realized through low cost production and high margin profit at the consumption end. At the present, khat does not seem to enjoy the low cost production that coffee, its historic rival, enjoyed in the Americas or the massive consumption sugar fetched in industrializing Europe. Only legal commodities could be commercialized and, as yet, khat still sits on a fence between licit and illicit substance.

\subsection{Unproven knowledge}

Thirdly, the lack of consensus or adequate knowledge about the social, medical and pharmacological effects of khat use will continue to defy classification internationally, denying the advocates of prohibition the moral and political support they would need to force the governments of the source countries to comply with international law. Much of the opposition depends on the health consequences of khat. The list of ailments that opponents ascribe to khat gives one the impression that no part of the human body, from the hair to the toes, escapes the dangerous effects of the evil leaves of the cursed tree. Khat seems to affect the nervous, digestive, respiratory, reproductive, cardiovascular systems, and other functions of the human body (Woldemichael, 2003).

At the moment, it seems that the scientific evidence is tentative with regard to khat's pharmacological effects and certainly more nuanced than the proponents of prohibition make it out to be. With regard to khat's effect on the human reproductive system, for instance, if we simply disregard the claims and counterclaims that khat is an aphrodisiac or anaphrodisiac, that it is an agent of impotence or sexual prowess, some studies suggest that it affects all semen parameters and produces abnormalities in sperm morphology (Islam et al., 1990; El-Shoura et al., 1995). Others show that khat actually stimulates sperm production, and had no deleterious effect on the testis (Al-Mamary et al., 2002). More recently, it was shown that some of the active chemicals in khat strengthened the sperm, suggesting that they may enhance natural fertility (AdeoyaOsiguwa and Fraser, 2005). The inconsistency in the findings aside, from the perspective of the khat eradication, it would be a practical contradiction and therefore an insurmountable challenge to convince khat farmers of Ethiopia or Yemen, regions with one of the highest fertility and annual population growth rates in the world, to give up their khat using the argument that doing so would restore their reproductive capacities.

The record is not just inconclusive when it comes to the effect of khat chewing on oral health, but also contradictory. Based on the length of time that khat quid remain in the mouth and the usually discolored teeth of chewers, many suggest that khat chewing must be detrimental to oral health. The studies on the oral health of khat chewers conducted in Yemen and Kenya show the prevalence of dental and periodontal diseases was generally lower among khat-chewers than non-chewers. Interestingly, the studies showed significantly lower periodontal and dental diseases in the chewing sides of the mouth of chewers, suggesting that khat had a beneficial effect on the chewing side or an adverse effect on the nonchewing side (Hill and Gibson, 1987; Jorgensen and Kaimenyi, 1990; Al-Hebshi and Skaug, 2005). The studies conclude that the oral hygiene status of khat chewers was generally better than that of non-chewers and there was no evidence to show that chewing is detrimental to periodontal health. A recent study based on a larger sample, focusing on Sana'a as opposed to several cities in Yemen as other studies have done, concluded that khat chewing can cause damage to the periodontal ligament as pocketing and gum recession (Mengel et al., 1996; Ali, 2007).

Similar inconsistencies exist in the studies on the effect of khat chewing on mental health. Some studies maintain that khat causes psychological disturbances (Alem and Shibre, 1997). Others acknowledge that khat chewers suffer mental disorders but see no direct association between chewing and any form of psychosis. This means the cause of the disorders could be attributed to a host of other factors. Many scholars working in this area concede that it is extremely difficult, if not impossible, to establish a cause and effect relationship between khat and mental disorder based on surveys and observations which suggest multi-factorial genesis of psychosis (Odenwald, 2007).

The ironies and inconsistencies in studies on other aspects of khat are equally startling. Khat is at the same time a boon for some and a bust for others; it is an innocuous habit for some, a toxic vice for others; a convenient escape from their conditions for the poor, an extravagant indulgence for the rich; khat provides a sense of incomparable bond among men, while causing loneliness in women. The paradox is apparent in a single chewer who experiences an idyllic exuberance and then slips into a melancholic introspection. It is an aphrodisiac for some men, an agent of impotence for others. States condemn it as a substance of addiction while addicted to it for revenue themselves. A chewer is often heard condemning khat while feverishly masticating it. The titles of some of the recent studies on khat tell a story about the uncertainty surrounding khat. Such titles as "The Elixir of Life or the Devil's Cud?," "The Devil's Cud or Farmers' Boon?," "Khat: a harmless Stimulant or an Addictive Drug; and Scourge of Life or an Economic Lifeline?," are fine examples of the ambivalence and tentativeness of our knowledge about khat. 
In general, the inconsistencies and tentativeness of studies of khat's effect suggest that there is not sufficient scientific knowledge about khat to warrant outlawing it internationally. As a result, khat is likely to remain a legal product in the Horn of Africa into the foreseeable future.

\subsection{Unforeseen consequences}

Fourthly, an international regime of prohibition would have disastrous consequences for the countries of the Horn of Africa. The history of prohibition of khat, or any other psychoactive substance, shows the only effective means of controlling the use of psychoactive substances is the wholesale eradication of the plant. The imposition of such a draconian measure, while it might show a slowdown in cultivation, requires the commitment of enormous resources which the weak governments of the Horn do not possess. Such an action would cause severe economic disruption in the producer countries and psychological distress for users in the consumer countries, provoking social unrest that the governments are ill-equipped to contain. Any change to the khat economy that challenges the status quo is bound to exacerbate the generally weak states of the Horn, some of which are engaged in existential struggle against militant opposition in a region that has been historically extremely volatile. The states are too fragile to conduct an effective campaign of eradication of the plant, the only effective measure against khat.

In regions outside the Horn of Africa, it is likely that more governments would make khat a controlled substance, among other reasons, for the purpose of enhancing national security and maintaining national identity (Anderson and Carrier, 2006, pp. 149-151; Carrier, 2007, pp. 195-200; Grayson, 2008, pp. 116-112). The overall effect would mean the Horn of Africa would be hemmed in by legal measures from the outside. A strong resistance from the Horn however, would create an island of legality where khat could be used, sold, and distributed.

Besides the social and economic dislocation that khat eradication would certainly engender, the Horn governments are aware, owing to their experience, that the goal of eradication is as unattainable as it is undesirable. The law enforcement approach has not been an effective means to eradicate dependence-producing substances. For instance, the United States has waged its "War on Drugs" for the last four decades and spent hundreds of billions of dollars on the fight. Yet the country's overall experience shows it has been more successful in regulating alcohol and tobacco than in its effort to eradicate coca at its source (Baum, 1997). The Horn of Africa has its share of failed government intervention to eradicate khat use. For instance, on 18 March 1983, Somalia enacted a law prohibiting the importation, cultivation, trade and consumption of khat on grounds that khat chewing had adverse effects on health and the socio-economic development of the country. The eradication effort did have measurable success in destroying khat plantations in the northwestern part of the country, but little effect on the number of people chewing khat. In any event, the government of Siad Barre was already in a political trouble by the time the law was enacted and simply bereft of any capacity to enforce it (Samatar, 1989, pp. 145-147).

This was not the first time that a law against khat was promulgated in Somalia. In 1921, and again in 1939, the cultivation, importation and possession of khat were prohibited. In the late 1949s and 1950s, British authorities in Somaliland sought to curb khat use in order to reduce its alleged adverse impact on productivity and public morality (Distefano, 1984, pp. 262-265).

Djibouti is a country where prohibition has been a complete failure. In the 1950s, the French Government considered banning the importation of khat from Ethiopia. Khat was in fact placed on the French government's list of narcotics in 1957. The measure was supposed to apply to all French-administered territories, including Djibouti, in proscribing any khat related activity. The Ethiopian government strongly protested the move. In view of Djibouti's dependence on Ethiopia for income as its chief port and the certainty of riots in the city, the territory's governor decided not to proceed with the implementation of the decree in his territory. Khat imports and consumption in Djibouti continued unabated (Brooke, 1960, p. 56)

It is evident that banning khat use and trade in the Horn of Africa would be a difficult task for any Horn government to enforce. It would be economically harmful and socially disruptive. More important, history shows prohibition does not bring about the desired result.

\section{Future trend}

Nearly two decades after khat chewing appeared in the West, there is little evidence that its use has crossed over to the indigenous populations in the host countries. The simple and obvious reason for this is that khat cannot compete with the panoply of more potent drugs that are available in the streets of Western cities in producing the desired high. The West has little to fear from khat because the mode of consumption of the leaves, the act of chewing all afternoon is a waste of time that will deliver too little effectiveness. A pill of amphetamine delivers more "bang for the buck" more effectively and inexpensively (Dhaifalah and Šantavý, 2004, p. 12). The fact that it takes hours to extract the active ingredient from the leaves makes khat an unattractive choice to the hectic way of life in the West.

If khat were to find new markets in the West it has to be either commercialized as a legally traded commodity, or evolve into a more efficiently consumed, more highly refined illicit product. The possibility that khat might be a legal commodity depends on its becoming a product people are willing to pay for. What are the odds that khat could become such a commodity? One of the stories about how the khat plant came to Yemen speaks volumes to the issue of what people are instinctively inclined to buy. The story begins with a Yemeni king, Muyya'ad al-Dau'd, asking an Ethiopian man to bring a khat plant to Yemen. The plant was brought and planted in Yemen, where it flourished. The Ethiopian told the Yemeni about the benefits of the khat leaves. "On learning that it banished the desire to eat, to drink or to have sexual relations, the king al-Mu'ayyad said: 'and what other pleasures are there in this life except these? I will never eat it! Those three things are all I spend my wealth on" (Cited in Weir, 1985, p. 72)

King Muyyaa'd is in good company in the contemporary world. In general, people are willing to pay more for these three than they would for other things. Even though it is now established that khat has spared many farmers from food shortages, it is not a food crop (Tefera et al., 2003). Therefore, the possibility that it might be developed into a food product, like chocolate, does not seem to be on the horizon.

Might khat succeed as beverage? In 2007, Reuters reported that an Ethiopian scientist was prepared to launch a new tipple made of khat leaves. In an interview with the reporter, the scientist said: "Khat wine is just as good as any wine produced from grapes and has been well-received by wine drinkers" (Bored of Bordeaux?, 2008). Asked if khatwine added the khat effect to the alcohol, the scientist pointed out that khat leaves do not retain their amphetamine-like qualities and khatwine is purely an alcoholic beverage.

Fortunately, I have had the opportunity to taste khatwine. While I do not claim to be a wine connoisseur, my assessment is that the product could be marketed as a new alcoholic beverage but it is extremely unlikely that it would be a popular wine substi- 
tute unless it is priced significantly lower than the going price for regular wine. My research around some Ethiopian blogs to verify the scientist's claim that his wine was well-received confirms my assessment and reveals a more difficult predicament for khatwine. The preponderance of the comments, while not denigrating khatwine, question the purpose of its existence. One blogger suggested: "whilst khat wine is a novel idea that would make a [sic] interesting summer drink, it is not really worth the effort for the result. It seems there is no weird scientific miracle that preserves the cathinone in wine and the concoction as suggested by other posters probably in fact only contains cathine (Santiago, 2007). Another added: "Apparently, they're saying that the wine will not have the amphetamine kick that I felt that night [after chewing khat], which strikes me as bull**, because why make it in the first place. Can't be for taste" (Awake, 2008).

With regard to the third element, that which relates to sex, a more promising report on the possibility of commercializing khat came in 2004 when researchers at the Centre for Reproduction, Endocrinology and Diabetes at King's College London announced their findings that chemicals in khat accelerated the process of sperm maturation and prolonged the sperm's fertilizing state. The lead researcher was confident that a product could be developed easily and emphasized that only small doses were needed for efficacy (Adeoya-Osiguwa and Frazer, 2004). There is potentially a good market for this product and a successful commercialization would have positive effects for khat farmers. However, it would take quite some time for the product to come on the market. Until then, khat would not be a commodity that people are willing to pay for.

In its proper context, khat is meant to be chewed in the company of friends. The market for the chewable leaves which now exists in the Horn of Africa and the Arabian Peninsula and in the emerging Somali and Ethiopian immigrant communities around the world is for this age-old purpose. Given the limited market and the restrictions on the creation of new markets, khat will remain a commodity marketable only in the original traditional-use area. Yet one scientific breakthrough in which natural cathinone is harnessed and concentrated, then all bets are off.

\section{References}

Adeoya-Osiguwa, S.A., Frazer, L., 2004. Cathine and norephedrine, both phenylpropanolamines, accelerate capacitation and then inhibit spontaneous acrosome loss. Human Reproduction 20, 198-207.

Advisory Council on the Misuse of Drugs, ACMD, 2005. Khat (Qat): Assessment of Risk to the Individual and Communities in the UK. Home Office, London.

Alem, A., Shibre, T., 1997. Khat induced psychosis and its medico-legal implication: a case report. Ethiopian Medical Journal 35, 137-141.

Al-Hebshi, N., Skaug, N., 2005. Effect of khat chewing on 14 selected periodontal bacteria in sub- and supragingival plaque of a young male population. Oral Microbiology and Immunology 20, 141-146.

Ali, A.A., 2007. Qat habit in Yemen Society: a causative factor for oral periodontal diseases. Internatioanl Journal of Environmental Research and Public Health 4, 243-247.

Ali, H., 1985. A Short Biography of Bejirond Takla Hawariat. Senior Essay. Department of History, Addis Ababa University.

Al-Mamary, M., Al-Habori, A.M., Al-Aghbari, M., Baker, M., 2002. Investigation into the toxicological effects of Catha edulis leaves: a short term study in animals. Phytotherapy Research 16, 127-132.

Anderson, D., Carrier, N., 2006. Contested Narrative of Khat Consumption. In Conusming Cultures, Global Perspectives: Historical Trajectories, Transnational Exchanges. Berg, Oxford \& New York, pp. 145-166.

Anderson, D., Beckerleg, S., Hailu, D., Klein, A., 2007. The Khat Controversy: stimulating the Debate on Drugs (Cultures of Consumption). Berg, Oxford.

Armstrong, E.G., 2008. Crime, chemicals, and culture: on the complexity of khat. Journal of Drug Issues, 631-648.

Arrafaine, M., 2004. Micro-macro economic analysis of "khat" production in Ethiopia. M.A. thesis, Department of Economics, Addis Ababa University. M.A. Thesis. Deparment of Economics, Addis Ababa University.

Awake, M., 2008. Khat Got Your Tounge? From Mik Awake: Unusually Tired (retrieved 30.09.09) http://mikawake.blogspot.com/2008/01/khat-got-yourtongue.html.
Baum, D., 1997. Smoke and Mirrors: The War on Drugs and the Politics of Failure Little Brown \& Co., Boston, MA.

Beckerleg, S., 2008. Khat special edition introduction. Substance Use and Misuse 42, 749-760.

Beke, C., 1843. On the countries south of Abyssinia. Journal of the Royal Geographical Society, 13.

Belew, M., Kebede, D., Kassaye, M., Enquoselassie, F., 2000. The magnitude of khat use and its association with health, nutrition and socio-economic status. Ethiopian Medical Journal 38, 11-26.

Bengall, S., 2006. Khat Dominates Male Life in the Tiny Muslim Nation of Djibouti., From McClatchy: (retrieved 09.08.09). http://www.mcclatchydc.com/ staff/shashank_bengali/story/13399.html.

Bored of Bordeaux?, 2008. Ethiopian to launch Khat "wine", From Reuters: (retrieved 01.10.09). http://www.reuters.com/article/lifestyleMolt/ idUSL0972672520080109.

Borelli, S., 2009. Social aspects of drug use in djibouti: the case of the leaf of Allah. Journal of African Economies 18, 555-591.

Brooke, C., 1960. Khat (Catha edulis): its production and trade in the Middle East. Geogaphical Journal 126, 52-59.

Brown, M., 2009. In Djibouti, everything stops for khat. The National, 1.

Burton, R., 1966 [1856]. First Footsteps in East Africa, Or An Exploration of Harar, vol. 2. Prager, New York

Carrier, N., 2007. A strange drug in a strange land. In: Vanderbroek, A.P. (Ed.), Traveling Cultures and Plants: The Ethnology and Ethnopharmacy of Human Migrations. Berghahn Books, New York \& Oxford, pp. 186-203.

Courtwright, D.T., 2001. Forces of Habit: Drugs and the Making of the Modern World. Harvard University Press, Cambridge, MA.

Davenport-Hines, R., 2001. The Pursuit of Oblivion: A Global History of Narcotics 1500-2000. Weidenfeld \& Nicolson, London.

Derfner, L., 1996. High on Gat: Gat chewing, an old Yemenite custom, is making a mark on Israeli Society. The Jerusalem Post, International Edition, 16-17.

Dhaifalah, I., Šantavý, J., 2004. Khat habit and its health effect. A natural amphetamine. Biomedical Papers 148.

Distefano, J., 1984. An enquiry into the history of qat. In: Labahn, T. (Ed.), Proceedings of the Second International Congress of Somali Studies. IV. Helmut Buske Verlag Hamburg, Hamburg, pp. 249-269.

Dizikes, C., 2009. Khat-Is it More Coffee or Cocaine?: The Narcotic Leaf is a Time-honored Tradition in Africa but Illegal in the U.S., Where Demand is Growing, From Los Angles Times: (retrieved 30.09.9). http://articles.latimes.com/ 2009/jan/03/nation/na-khat3.

El-Mahi, T., 1972. A Preliminary Study on Khat Together with Institutional History of Coffee as a Beverage in Relation to Khat. WHO Regional Office for Eastern Mediterranean, Alexandria.

Elmi, A.S., 1984. Khat: history, spreading and problems in Somalia. In: Labahn, T. (Ed.), Proceedings of the Second International Congress of Somali Studies. Helmut Buske Velag, Hamburg, p. p. 274.

El-Shoura, et al., 1995. Deleterious effects of khat addiction on semen parameters and sperm ultrastructure. HumanReproduction 10, 2295-2300.

Fedarko, K., 2006. High in Hell. Esquire., http://www.esquire.com/features/ ESQ0906KHAT_182.

Férret, P.V.A., Galineir, J.G., c. 1848. Voyage en Abyssinie, dans les provinces du Tigre, du Semen et de l'Amhara, vol. 3, Paris: Paulin.

Gardiner, S., 2006. That darned khat: in search of New York City's most illusive drug. The Village Voice.

Gebissa, E., 2004. Leaf of Allah: Khat and Agricultural Transformation in Harerge, Ethiopia, 1875-1991. James Currey, Oxford.

Geshekter, C., 1985. Anti-colonialism and class formation: the eastern horn of Africa before 1950. International Journal of African Historical Studies 18, 1-32.

Grayson, K., 2008. Chasing Dragons: Security, Identity, and Illicit Drugs in Canada. University of Tronto Press, Toronto.

Harris, C.W., 1844. The Highlands of Aethiopia, vol. 3. London: Longman, Brown, Green, and Longmans.

Hill, C.M., Gibson, A., 1987. The oral and dental effects of qat chewing. Oral Surgery, Oral Medicine, Oral Pathology, Oral Radiology and Endodontology 63 , 433-436.

Hassan, M.S., 2001. Khat-an evil from hell, or the food of the saints: economic and social implications. In: Janzen, J. (Ed.), What Are Somalia's Development Perspectives: Science Between Resignation and Hope. Das Arbish Bush, Berlin, pp. 191-200.

Islam, et al., 1990. An evaluation of the male reproductive toxicity of cathinone. Toxicology 60 (3), 223-234

Jorgensen, E., Kaimenyi, J.T., 1990. The status of periodontal health and oral hygiene of Miraa (Catha edulis) chewers. East African Medical Journal 67, 585-590.

Kimball, J., 2007. Narcotic Khat Dominates Djibouti Life, From Reuters: (retrieved 09.08.09) http://www.reuters.com/article/latestCrisis/idUSL27176585.

Mengel, R., Eigenbrodt, M., Schünemann, T., Flores-de-Jacoby, L., 1996. Periodontal status of a subject sample of Yemen. Journal of Clinical Periodontology 23, 437-443.

Mintz, S., 1986. Sweetness and Power: The Place of Sugar in Modern History. Penguin, New York.

Moktar, M. 1876. Notes sur le pays de Harrer. Bulletin de la société Khédiviale de Géographie 1, 369-372.

Nasrulla, A., 2000. Khat: harmless stimulant or addictive drug? Journal of Addictions and Mental Health, 1-10.

Odenwald, M., 2007. Chronic khat use and psychotic disorders: a review of the literature and future prospects. SUCHT 53, 9-22. 
Pendergrast, M., 2000. Uncommon Grounds: The History of Coffee and How It Transformed Our World. Basic Books, New York.

Samatar, A.I., 1989. The State and Rural Transformation in Northern Somalia, 1884-1986. University of Wisconsin Press, Madison.

Smith, M.L., et al., 1992. Why People Grow Drugs: Narcotics and Development in the Third World. Panos Institute, London.

Santiago (Ed.), 2007. The Corroborre. http://www.shaman-australis.com/ forum/index.php?showtopic=13722\&mode=threaded\&pid=227670 (retrieved 30.09.08).

Steinberg, M.K., 2004. Introduction. In: Steinberg, M.J. (Ed.), Dangerous Harvest: Drug Plants and the Transformation of Indigenous Landscapes. Oxford University Press, New York, pp. 3-8.

Summers, C., 2006. Harmless Habit or Dangerous Drug?, From BBC News: (retrieved 30.09.09) http://news.bbc.co.uk/2/hi/uk_news/4615415.httm.
Tefera, T.L., Kirsten, J.F., Perret, S., 2003. Market incentives, farmers' response and a policy dilemma: the case study of expansion of chat production in the Hararghe highlands, eastern Ethiopia. Agrekon 42, 213-227.

Thompson, V., Adloff, R., 1968. Djibouti and the Horn of Africa. Stanford University Press, Stanford.

UNODC U.N., 2008. Amphetamine-type Stimulants: A Global View (retrieved 09.07.2009) http://www.unodc.org/undoc/technical_series_1996-0101_1.html.

Weir, S., 1985. Qat in Yemen: Consumption and Social Change. British Museum Press, London.

WHO Expert Committee on Drug Dependence, 2006. Thirty-fourth Report. WHO Technical Report Series. World Health Organization, Geneva.

Woldemichael, W., 2003, December 26. Health hazards associated with khat consumption. Addis Tribune, 8-9. 